\title{
Clinical assessment of hypertension in children
}

\author{
Nisarg Patel ${ }^{*}$ and Nicole Walker
}

\begin{abstract}
The use of blood pressure measurements have become a routine part of physical exam for the evacuation of cardiovascular health adults and, more recently, children. The most widely used definition of hypertension is delineate as greater than $90 \%$ BP according to age, sex, and height by the National High Blood Pressure Education Program. Current research suggests that pediatric hypertension is influenced by multitude of factors including birth weight, maturity during birth, heredity, and diet leading to primary hypertension. Factors influencing secondary hypertension include renal abnormalities, coarctation of the aorta, medications, neoplasm, etc. The treatment for pediatric hypertension is carried out with diet and exercise as the first line of defense. Only under non-compliance with diet and exercise is pharmaceutical intervention appropriate. This paper outlines a concise summary of the current understanding and research for scientists, clinicians, as well as for the general population to better understand pediatric hypertension.
\end{abstract}

Keywords: Pediatric Hypertension, Primary Hypertension, Secondary Hypertension, Clinical assessment, Hypertension, Children, Pediatrics, Primary practice, Cardiology, Family medicine

\section{Background}

Blood pressure measurements for adults have proven to be crucial in the assessment of cardiovascular health, and since Stephen Hales' experiments in the eighteenth century, have become a routine part of physical exam [1]. However, it wasn't until 1977 that proper assessment of hypertension in children was carried out by the Task Force on Blood Pressure Control in Children [2]. Since then, numerous studies have been conducted to better understand hypertension in children. We will layout a concise summary of the current understanding and research for scientists, clinicians, as well as for the general population to better understand pediatric hypertension.

\section{Definition and prevalence of hypertension in children}

In 2004, the National High Blood Pressure Education Program published its fourth report on hypertension in children with detailed definitions of pediatric hypertension [3]. This definition utilizes specific age, sex, and height to define the $50^{\text {th }}, 90^{\text {th }}, 95^{\text {th }}$, and $99^{\text {th }}$ percentile blood

\footnotetext{
* Correspondence: Patel1804@gmail.com

Philadelphia College of Osteopathic Medicine (PCOM), Suwanee, GA 30024, USA
}

pressure (BP) data tables to determine normal BP. [3]. This report defines hypertension as over $90 \% \mathrm{BP}$ ccording to age, sex, and height [3].

Using the most current definition of hypertension in children, studies have found the prevalence to range between 4.7 and $19.4 \%$ depending on a variety of factors such as age, sex, ethnicity, body mass index (BMI), parental hypertensive status, etc. $[4,5]$. Hypertensive and pre-hypertensive status closely followed BMI [4]. Prevalence of hypertension highest among Hispanics $(25 \%)$ and lowest among (14\%) [5]. The explosion of obesity among children, 5 to $11 \%$ from 1960s to 1990 s, has caused a dramatic increase in hypertension among children [6]. Studies indicate that more than $20 \%$ of children that are obese have pri(7). This trend of increased childhood disity will continue to have a dramatic impact on the cardiovascular health of American children and is something

\section{Factors influencing blood pressure in children}

Blood Pressure varies widely during a child's development with an overall steadily increasing trend. The average systolic blood pressure at birth is approximately $70 \mathrm{mmHg}$ which increases to $85 \mathrm{mmHg}$ by one month of age [8]. 
Blood pressure in premature infants is considerably lower and is directly related to the weight [9]. Previous research has shown a significant inverse relationship between birth weight and risk for hypertension later in life placing premature infants in the greater risk category [10]. Starting during preschool age, children seem to be placed in a percentile distribution that they tend to follow throughout their life giving weight to the theory that essential hypertension begins in childhood [11].

As with adult hypertension, traditional separation of primary and secondary classification is useful for children. Children with secondary hypertension have a specific, potentially correctable, abnormality responsible for their high blood pressure while those with primary or essential hypertension do not.

\section{Primary hypertension}

Primary hypertension affects millions around the world. Our inability to identify the cause of elevated blood pressure in primary hypertension undoubtedly reflects both the complex physiologic process that regulates blood pressure and the heterogeneous nature of this disorder [12].

One of the most important factors influencing primary hypertension in children is heredity $[4,9,12,13]$. Children with paternal and/or maternal history of hypertension demonstrated significant risk for developing primary hypertension before the age of 18 [4]. There is a greater influence of heredity from paternal side than from maternal side [4]. However, other studies have found the opposite to be true leaving no significant consensus on this matter in the scientific community [9]. The inheritance pattern for hypertension seems to be multifactorial and is modified by environmental factors [13].

Diet has also been linked to primary hypertension in children. Multiple studies show a significantly higher percent of hypertensive children with non-vegetarian diet $[4,14]$. Decades of research have also correlated high sodium intake and high blood pressure $[4,9,12,13]$. The sensitivity of sodium on hypertension appears to be genetically determined as well [13].

The relationship between obesity and hypertension in children is well documented since the 80 's. Current studies indicate that overweight children and adolescents are at a substantially increased risk for several Cardiovascular Disease (CVD) risk factors. The association between obesity and high systolic blood pressure (SBP) among 2 to 9 year old children appears to be stronger than in adolescents [7]. The pathophysiology of obesity-associated hypertension has not been clearly defined. Research indicates that insulin resistance and hyperinsulinemia might contribute to enhanced renal sodium reabsorption or increasing sympathetic nervous system activity [15].

\section{Secondary hypertension}

Secondary hypertension is accompanied with pathology or medications that could be correlated to the hypertension. Secondary hypertension is more common than primary hypertension in infants and young children. In fact, up to $85 \%$ of children with hypertension have an identifiable cause [16]. It is the recommendation that all children with confirmed hypertension be evaluated for underlying causes to include renal parenchymal disease [16]. Table 1 cites common causes of secondary hypertension in children $[12,13,17]$.

The causes of hypertension vary with age. Renal artery thrombosis or stenosis, congenital renal malformations, or coarctation of aorta present with newborn hypertension [13]. While these conditions present with obvious signs and symptoms, studies indicate a significant delay in the diagnosis due to improper assessment of blood pressure by physicians [12]. Children older than 6 years of age, renal artery stenosis and renal parenchymal are

Table 1 Most common causes of secondary hypertension by age

\begin{tabular}{ll}
\hline Age group & Etiology \\
\hline Newborn - First year & Renal artery or venous thrombosis \\
& Renal artery stenosis \\
& Congenital renal abnormalities \\
& Coarctation of the aorta \\
& Bronchoplumonary dysplasia \\
& Renovasular disease \\
& Renal parenchymal disease \\
& latrogenic \\
& Tumor \\
& Renal parenchymal disease \\
& Renovascular disease \\
First to 6 years & Coarctation of the aorta \\
& Tumor \\
& Endocrine causes \\
& latrogenic \\
& Essential hypertension \\
Age 10 to 18 years & Renal parenchymal disease \\
& Essential hypertension \\
& Renovascular disease \\
& Coartctation of the aorta \\
& Endocrine causes \\
& Tumor \\
& Essential hypertension \\
& latrogenic \\
& Renal parenchymal disease \\
& Endocrine causes \\
& Coartctation of the aorta \\
\hline & \\
\hline
\end{tabular}


the leading definable causes of diastolic blood pressure measurements in excess of 90 to $100 \mathrm{mmHg}$ [12]. Approximately $75-80 \%$ of children with secondary hypertension have a renal abnormality [18]. In adolescent females, oral contraceptives have been associated with hypertension. The stimulation of renin-angiotensionaldosterone system as well as other related pathologies leading to secondary hypertension are listed in Table 1 [19].

\section{Ambulatory blood pressure monitoring}

Traditionally, blood pressure measurements have been taken while the patient was at the office, but these practices only demonstrate the pressure in a certain setting. In children, these recorded blood pressures can be vastly different from when the child is at home or during their daily routines. Ambulatory blood pressure monitoring (ABPM) can show blood pressures at various times throughout the day and in various settings ([20].) Because ABPM can allow the clinician to get an accurate pattern of blood pressure in the patient, ABPM can be helpful in predicting target-organ damage, and may be a more accurate blood pressure measurement $[20,21]$. In healthy children, ABPM has demonstrated significantly improved daytime SBP and DBP, along with a lower $H R$, as a result of a simple breathing meditation intervention [21]. While multiple singlecenter case series have demonstrated the usefulness of ABPM in identifying persistently hypertensive youths with normal clinic BP, large-scale pharmacologic trials in children utilizing ABPM have not been reported [21].

\section{Hypertension and target-organ damage}

Prolonged hypertension can impact many organs if left unresolved. Organs and structures at risk are: heart, kidney, vascular walls, and the nervous system [22]. Childhood and adolescent hypertension is linked to future target-organ damage [21]. Target-Organ damage can include, but is not limited to carotid intima-media thickness, left ventricular mass, arterial stiffness, and left ventricle hypertrophy [21]. In children and adolescents with hypertension, it is essential to assess target-organs for any changes [22].

\section{Symptoms}

Children with hypertension rarely have clinical evidence of the disease. The increased blood pressure is usually detected during a normal examination or before a physical examination for sports participation. Children with secondary hypertension present as asymptomatic unless the pressure is sustained or raising rapidly [18]. Clinical manifestations of underlying diseases include such things as failure to thrive and failure to grow [18].
Significant elevation of blood pressure can lead to headaches, dizziness, visual changes, nausea, epistasis, and seizures [13].

\section{Treatment}

Once a definitive diagnosis of pre-hypertension or hypertension has been established, a treatment regimen must be outlined. As previously mentioned, increased BMI is closely related to hypertension, so if the hypertensive child is obese, a weight loss plan should be established [23]. Weight loss plans can include increased physical activity, diet modification, and behavioral therapies [23].

If diet and lifestyle changes fail to resolve hypertension after more than 6 months, this could be an indication that additional pharmacologic treatment is needed [24]. Other indications for pharmacologic treatment in adolescents include diabetes mellitus, chronic kidney disease, and stage II hypertension [24]. The use of pharmacologic treatment in pediatrics is controversial and should only be used when diet and exercise were not successful. Primary medications to consider for first line treatment are: angiotensin-converting enzyme (ACE) inhibitor, calcium channel blocker, angiotensin II receptor blocker (ARB), diuretic, and beta blocker drug classes [24].

If a secondary pharmacologic therapy is needed, the selection of this medication will need to be based on the primary medication chosen due to medication interactions and comorbidities [24].

\section{Conclusion}

Hypertension in children and adolescents is a rising health concern that should be taken seriously and diagnosed early. With obesity on the rise, we can only conclude that the issue of prehypertension and hypertension will increase as well. With the introduction of increased physical activity and a well balanced diet, we are optimistic that obesity and thus hypertension can be treated without the need for additional pharmacologic intervention.

\section{Abbreviations}

ACE: angiotensin converting enzyme; ARB: angiotensin II receptor blocker; BMI: body mass index; BP: blood pressure; CVD: cardiovascular disease; SBP: systolic blood pressure.

Competing interests

The authors declare that they have no competing interests.

Authors' contributions

NP carried out the background research necessary as well as writing majority of the article. NW assisted with completing the treatment section, assisted with proofreading and working on reviewer suggestions and corrections. Both authors read and approved the manuscript.

Received: 29 December 2015 Accepted: 25 March 2016

Published online: 17 May 2016 


\section{References}

1. Booth J. A short history of blood pressure measurement. Proc Royal Soc Med. 1977;70(11):793-9.

2. National Heart, Lung, and Blood Institute's Task Force on Blood Pressure Control in Children. Report of the Task Force on Blood Pressure Control in Children. Pediatrics 1977; 797-820.

3. National High Blood Pressure Education Program Working Group on High Blood Pressure in Children and Adolescents. The fourth report on the diagnosis, evaluation, and treatment of high blood pressure in children and adolescents. Pediatrics. 2004;114:555-76.

4. Amritanshu K, Kumar A, Pathak A, Garg N, Banerjee P D. Prevalence and risk factors associated with hypertension in children and adolescents. Pediatric Oncall. 2015.

5. Sorof JM, Lai D, Turner J, Poffenbarger T, Portman RJ. Overweight, ethnicity, and the prevalence of hypertension in school-aged children. Pediatrics. 2004;113(3):475-82.

6. McNiece KL, Poffenbarger TS, Turner JL, Franco KK, Sorof JM, Portman RJ. Prevalence of hypertension and pre-hypertension among adolescents. J Pediatr. 2007;150(6):640-4.

7. Sypniewska G. Laboratory assessment of cardiometabolic risk in overweight and obese children. Clin Biochem. 2015;48(6):370-6.

8. Zinner SH, Rosner B, Oh W, Kass EH. Significance of blood pressure in infancy: familial aggregation and predictive effect on later blood pressure. Hypertension. 1985;7:411-6.

9. Sinaiko AR. Hypertension in children. N Engl J Med. 1996;335(26):1968-73.

10. Mu M, Sheng J, Zhao Y, Li H, Hu C, Tao F. Birth weight and subsequent blood pressure: A meta-analysis. Arch Cardiovasc Dis. 2012;105(2):99-113.

11. Julius S, Jamerson K, Mejia A, Krause L, Schork N, Jones K. The association of borderline hypertension with target organ changes and higher coronary risk: Tecumseh Blood Pressure study. JAMA. 1990;264:354-8.

12. Feld LG, Springate JE. Hypertension in children. Curr Probl Pediatr. 1988;18(6):323-73.

13. Coody DK, Yetman RJ, Portman RJ. Hypertension in children. J Pediatr Health Care. 1995;9(1):3-11.

14. Agarwal AK, Yunus M, Khan A, Ahmad J. A clinical-epidemiological study of hypertension in rural population of jawan block, Distt Aligarh (UP). India J R Soc Health. 1994;114:17-9.

15. Rao A, Pandya V, Whaley-Connell A. Obesity and insulin resistance in resistant hypertension: implications for the kidney. Adv Chronic Kidney Dis. 2015;22(3):211-7.

16. Viera AJ, Neutze DM. Diagnosis of secondary hypertension: an age-based approach. Am Fam Physician. 2010;82(12):1471-8.

17. Gupta-Malhotra M, Banker A, Shete S, Hashmi SS, Tyson JE, Barratt MS, et al. Essential hypertension vs secondary hypertension among children. Am J Hypertens. 2015;28(1):73-80.

18. Behrman R, Kliegman R. Nelson textbook of pediatrics. 14th ed. Philadelphia: W.B. Saunders; 1992. p. 251-306.

19. Portman RJ, McNiece KL, Swinford RD, Braun MC, Samuels JA. Pediatric hypertension: diagnosis, evaluation, management, and treatment for the primary care physician. Curr Probl Pediatr Adolesc Health Care. 2005;35(7):262-94.

20. Portman R, Yetman R. Clinical uses of ambulatory blood pressure monitoring. Pediatr Nephrol. 1994;8:367-76.

21. Flynn JT, Daniels SR, Hayman LL, Maahs DM, McCrindle BW, Mitsnefes M, et al. Update: Ambulatory Blood Pressure Monitoring in Children and Adolescents. Hypertension. 2014;63:1116-35.

22. Lurbe E. Hypertension and target organ damage in children and adolescents. J Hypertens. 2007;25(10):1998-2000

23. Sorof J, Daniels S. Obesity hypertension in children: a problem of epidemic proportions. Hypertension. 2002;40:441-7.

24. Gralia N, Yehle K, Ahmed A, Ross M. Managing hypertension among obese children in primary care: updated evidence. J Nurse Pract. 2015:11(3):328-34. 